\title{
ARMAZENAMENTO A VÁCUO PROLONGA A VIABILIDADE DE SEMENTES DE JABUTICABEIRA ${ }^{1}$
}

\author{
MOESES ANDRIGO DANNER ${ }^{2}$, IDEMIR CITADIN³, SIMONE APARECIDA ZOLET SASSO ${ }^{4}$, \\ RODRIGO AMBROSIO 5 , AMÉRICO WAGNER JÚNIOR ${ }^{3}$
}

RESUMO: O objetivo deste trabalho foi avaliar a viabilidade de sementes de jabuticabeira (Plinia cauliflora) sob diferentes condições de armazenamento. Para isso, foram realizados dois experimentos. No primeiro, testou-se a viabilidade de sementes armazenadas sob três diferentes temperaturas (temperatura ambiente, $12^{\circ} \mathrm{C}$ e $6^{\circ} \mathrm{C}$ ) e períodos de armazenamento $(5 ; 10 ; 20 ; 40$ e 80 dias após a extração das sementes). No segundo experimento, testou-se a viabilidade de sementes armazenadas a vácuo sob três condições (com água esterilizada, com tampão fosfato $\mathrm{pH} 7,0$ e a seco) e períodos de armazenamento $(5 ; 20 ; 35 ; 50$ e 65 dias após a extração das sementes). Sob atmosfera normal, as sementes de jabuticabeira conservam viabilidade por apenas cinco dias, com maior emergência sob temperatura ambiente $(83,35 \%)$. As sementes de jabuticabeira perdem totalmente a viabilidade com teor de umidade próximo a 10\%. As sementes de jabuticabeira armazenadas a vácuo com tampão fosfato mantêm razoável viabilidade (41,6\%) até 65 dias de armazenamento.

Termos para indexação: Plinia cauliflora, semente recalcitrante, teor de umidade, conservação da semente.

\section{STORAGE IN VACUUM ENHANCE SEED VIABILITY OF JABUTICABA TREE}

\begin{abstract}
The objective of this study was to evaluate the viability of seeds of jabuticaba tree (Plinia cauliflora) under different storage conditions. For this, two experiments were conducted. In the first, it was tested the viability of seeds stored under three different temperatures (room temperature, $12^{\circ} \mathrm{C}$ and $6^{\circ} \mathrm{C}$ ) and five storage periods $(5,10,20,40$ and 80 days after seeds extraction). In the second experiment, it was tested the viability of seeds stored in polypropylene bags in vacuum with three conditions (with sterile water, with phosphate buffer $\mathrm{pH} 7.0$ and in dry) and storage periods (5, 20, 35, 50 and 65 days after seeds extraction). Under normal atmosphere, the seeds of jabuticaba tree kept viability for only five days, with higher emergence at room temperature (83.35\%). Seeds of jabuticaba tree totally lose viability with water content near $10 \%$. Seeds of jabuticaba tree stored in vacuum with phosphate buffer kept a reasonable viability (41.6\%) up to 65 days of storage.
\end{abstract}

Index terms: Plinia cauliflora, recalcitrant seed, seed water content, seed conservation.

\section{INTRODUÇÃO}

A jabuticabeira é originária do centro-oeste/ sul/sudeste do Brasil e pertence à família Myrtaceae. São conhecidas nove espécies de jabuticabeira, dentre as quais se destaca Plinia cauliflora (DC) Berg, conhecida como jabuticabeira paulista ou jabuticabeira-açu (MATTOS, 1983). Esta espécie apresenta dispersão natural em alguns municípios da região sudoeste do Paraná.

O potencial de comercialização da jabuticaba é grande em função de suas características organolépticas (MAGALHÃES et al., 1996), sendo apreciada tanto para consumo in natura como para a fabricação de geleia, suco, sorvete, bebidas fermentadas e licores. A casca dos frutos apresenta elevado conteúdo de antocianinas (TEIXEIRA et al., 2008), com potencial de utilização na indústria alimentícia, de cosméticos e farmacêutica.

Mesmo considerando os avanços obtidos na propagação assexuada da jabuticabeira (DUARTE et al., 1997; DANNER et al., 2006; SASSO et al., 2010), na prática, o principal método de obtenção de mudas da espécie ainda é por sementes, por ser uma espécie de difícil enraizamento de estacas (SCARPARE FILHO et al., 1999; SASSO, 2009).

Porém, as sementes da jabuticabeira perdem rapidamente a viabilidade (VALIO; FERREIRA,

'(Trabalho 053-10). Recebido em: 18-02-2010. Aceito para publicação em:12-08-2010.

${ }^{2} \mathrm{Eng}^{\mathrm{o}}$. Agr ${ }^{\mathrm{o}} \mathrm{MSc}$., Doutorando em Agronomia UFPR. Bolsista Capes. moesesandrigo@yahoo.com.br

${ }^{3} \mathrm{Eng}^{\mathrm{o}}$. Agr ${ }^{\circ}$. Dr. em Agronomia. Programa de Pós-Graduação em Agronomia, UTFPR, Câmpus Pato Branco. Via do conhecimento, km 01. CEP: 85501-970. Pato Branco-PR. Emails: idemir@utfpr.edu.br, americowagner@utfpr.edu.br ${ }^{4} \mathrm{Eng}^{\mathrm{o}}$. Agr ${ }^{\circ}$ MSc. UTFPR, Câmpus Pato Branco. E-mail: iosasso@ibest.com.br

${ }^{5}$ Estudante de Agronomia. UTFPR, Câmpus Pato Branco. E-mail: rodrigoambrosio87@hotmail.com 
1992), o que as caracteriza como sementes recalcitrantes. Como as sementes recalcitrantes se deterioram rapidamente, mesmo com a manutenção da umidade, métodos especiais de conservação e armazenamento devem ser estudados.

Dessa forma, estudos para prolongar o período de armazenamento das sementes de jabuticabeira assumem fundamental importância, visando a seu uso na obtenção de porta-enxertos, na manutenção da variabilidade para uso no melhoramento genético e para utilização em reflorestamentos e pomares comerciais. Porém, esses estudos são escassos, o que dificulta a definição de estratégias para a conservação das sementes, mesmo por curtos períodos.

O objetivo deste trabalho foi avaliar a viabilidade de sementes de jabuticabeira (Plinia cauliflora) sob diferentes condições de armazenamento.

\section{MATERIAL E MÉTODOS}

Foram realizados dois experimentos, visando a manter a viabilidade de sementes de jabuticabeira (Plinia cauliflora) sob armazenamento. Nos dois experimentos, as sementes foram extraídas de frutos totalmente maduros (coloração preto-arroxeada da casca), de plantas nativas localizadas em VitorinoPR ( $26^{\circ} 19^{\prime} \mathrm{S} ; 52^{\circ} 46^{\prime} \mathrm{W}$; altitude $\left.820 \mathrm{~m}\right)$. Após a extração, as sementes foram despolpadas com cal virgem, lavadas, submetidas à desinfestação com hipoclorito de sódio $(1,25 \%)$, por 10 minutos, e colocadas sobre papel toalha durante 12 horas, para retirada do excesso de água.

\section{Experimento 1}

Para o experimento 1, os frutos foram coletados em setembro de 2006. Após extração, foram selecionadas as sementes de maior tamanho (massa média de $215 \pm 25 \mathrm{mg}$ ), divididas em lotes de 15 sementes cada e colocadas em sacos de papel kraft.

As sementes foram submetidas a diferentes temperaturas de armazenamento: temperatura ambiente $\left(17^{\circ} \mathrm{C} \pm 4^{\circ} \mathrm{C}\right), 12^{\circ} \mathrm{C}$ e $6^{\circ} \mathrm{C}$. Para armazenamento em temperatura controlada, utilizaram-se estufas incubadoras tipo B.O.D. Os períodos de armazenamento foram de $5 ; 10 ; 20$; 40 e 80 dias após a extração das sementes. Determinou-se o percentual de umidade de quatro amostras de 15 sementes, na data da coleta e após cada período de armazenamento, em estufa com circulação forçada de $\operatorname{ar}\left(\right.$ a $\left.50^{\circ} \mathrm{C} \pm 3^{\circ} \mathrm{C}\right)$, até peso constante (aproximadamente sete dias).

Depois da retirada das sementes de cada condição de armazenamento, o experimento foi conduzido em casa de vegetação, na Universidade
Tecnológica Federal do Paraná (UTFPR), Câmpus Pato Branco, em delineamento inteiramente casualizado, com quatro repetições de 15 sementes cada. A semeadura foi realizada a um $\mathrm{cm}$ de profundidade, em bandejas de isopor (células de $100 \mathrm{~cm}^{3}$ ), contendo como substrato Plantmax ${ }^{\circledR}$ Hortaliças. Cada célula recebeu uma semente. Isso foi efetuado também na data de coleta (sem armazenamento), visando a verificar a viabilidade inicial das sementes. A irrigação foi efetuada diariamente, mantendo o substrato sempre úmido.

Procedeu-se à contagem de plantas emergidas a cada cinco dias, a partir do início da emergência $\left(35^{\circ}\right.$ ao $50^{\circ}$ dia após semeadura) até aproximadamente o $150^{\circ}$ dia da semeadura. Para o cálculo do índice de velocidade de emergência (IVE), consideraram-se os dados até a data de estabilização da emergência (aproximadamente aos 120 dias após semeadura). Efetuou-se também a avaliação do percentual de emergência (número de plantas emergidas/número de sementes semeadas) e do percentual de poliembrionia (número de sementes que deram origem a mais de uma planta/número de sementes que originaram plantas), ao final do experimento.

Os dados de emergência, IVE e poliembrionia foram submetidos aos testes de adequação aos pressupostos do modelo matemático: teste de sequência, para verificar a aleatoriedade dos erros; teste de Lilliefors, para verificar a normalidade da distribuição dos erros; e teste de Bartlett, para verificar a homogeneidade das variâncias residuais entre os tratamentos (STEEL; TORRIE, 1960). Em seguida foi procedida a análise de variância, considerando apenas os dados de cinco dias após armazenamento das sementes, visto que, nas demais datas, não houve emergência. As médias das diferentes temperaturas de armazenamento foram comparadas entre si, pelo teste de Scott-Knott $(P \leq 0,05)$, utilizando o programa 'Genes' (CRUZ, 2006).

\section{Experimento 2}

Para o experimento 2, os frutos foram coletados em setembro de 2008. Após extração, foram selecionadas as sementes de maior tamanho (massa média de semente $=198 \pm 18 \mathrm{mg}$ ) e divididas em subamostras de 15 sementes cada.

As sementes foram embaladas a vácuo, em sacos de polietileno $(80 \mu$ de espessura), sob três condições: com água destilada esterilizada $(10 \mathrm{~mL}$ por saco), tampão fosfato $\mathrm{pH}$ 7,0 (10 $\mathrm{mL}$ por saco) ou mantidas a seco. As embalagens foram mantidas sob temperatura controlada de $12^{\circ} \mathrm{C}$, em estufa incubadora tipo B.O.D. Testaram-se também períodos de armazenamento de 5; 20; 35; 50 e 65 dias após 
extração das sementes. Determinou-se o percentual de umidade das sementes na data de extração e após cada período de armazenamento, da mesma forma que no primeiro experimento.

Depois da retirada das sementes de cada condição e período de armazenamento, o experimento foi conduzido no mesmo local e utilizando mesma metodologia do experimento anterior.

Os dados de emergência, IVE e poliembrionia foram submetidos aos testes de adequação aos pressupostos do modelo matemático, da mesma forma que no primeiro experimento. Os dados de percentual de poliembrionia foram transformados em $\log _{10}(\mathrm{x})$. Em seguida, foi procedida a análise de variância, em esquema bifatorial $(3 \times 5)$, sendo três condições e cinco períodos de armazenamento das sementes. Quando adequado, foram ajustadas equações de regressão, utilizando o programa 'Genes' (CRUZ, 2006).

\section{RESULTADOS E DISCUSSÃO}

\section{Experimento 1}

Para a avaliação dos dados de emergência, IVE e poliembrionia, não foi necessário utilização de transformação, pois os mesmos foram adequados a todos os pressupostos do modelo matemático.

Observou-se que as sementes de jabuticabeira perderam totalmente sua viabilidade quando armazenadas por mais de cinco dias, independentemente da temperatura utilizada, o que denota típico comportamento de sementes recalcitrantes (ROBERTS, 1973a). Das sementes armazenadas por cinco dias, observou-se que aquelas submetidas a temperatura ambiente mantiveram maior viabilidade e vigor, pois tiveram emergência e índice de velocidade de emergência (IVE) significativamente superiores às temperaturas de armazenamento de $12^{\circ} \mathrm{C}$ e $6^{\circ} \mathrm{C}$. A taxa de poliembrionia foi, em média, de $29,2 \%$ e não foi afetada significativamente pelas temperaturas, o que pode ser relacionado ao alto coeficiente de variação obtido, 112,4\% (Tabela 1). Das sementes poliembriônicas, houve emergência de duas até cinco plantas, sendo mais frequente o menor número. Gurgel e Soubihe Sobrinho (1951) observaram variação no percentual de poliembrionia entre genótipos de três espécies de jabuticabeira, coletados em diferentes locais de São Paulo, que foi de 15 a $72 \%$, inclusive com variação entre anos de coleta para os mesmos genótipos. Isso indica a presença de forte influência ambiental na expressão da poliembrionia, o que pode explicar o alto $\mathrm{CV}(\%)$ encontrado no presente experimento.

O teor inicial de água das sementes (sem armazenamento) foi de $42,1 \%$, proporcionando emergência de $100 \%$ e IVE de 0,56 , quando a semeadura foi efetuada logo após a extração dos frutos. No $5^{\circ}$ dia de armazenamento, a umidade já estava reduzida, em média, a $16,4 \%$, nas três temperaturas (Tabela 2). Portanto, observou-se que as sementes perderam rapidamente o teor de água.

Comparando as Tabelas 1 e 2, observa-se que a maior emergência $(83,4 \%)$, obtida sob temperatura ambiente, coincide com o maior teor de umidade das sementes $(19,6 \%)$. As sementes armazenadas por 5 dias a $6^{\circ} \mathrm{C}$ apresentaram menor percentual de emergência e IVE, devido a seu teor de umidade situar-se em torno de $13,7 \%$. A partir do $10^{\circ}$ dia de armazenamento, não houve emergência, coincidindo com níveis de umidade das sementes abaixo de 10\%. Valio e Ferreira (1992) também verificaram que a germinação de sementes de jabuticabeira está associada ao teor de água das mesmas. Porém, observaram que as sementes não germinaram com grau de umidade de $20,7 \%$, o que difere do presente experimento. Isso pode ser explicado, pois os autores observaram a germinação das sementes apenas até o $12^{\circ}$ dia da incubação em condições de temperatura controlada. Provavelmente, se a avaliação tivesse sido realizada por um período maior de tempo, haveria germinação, pois o IVE também é reduzido em sementes com baixo teor de umidade, ou seja, sua emergência é mais lenta. Os mesmos autores observaram que a perda de eletrólitos e de substâncias orgânicas está relacionada de forma inversamente proporcional ao grau de umidade das sementes de jabuticabeira. A perda dessas substâncias indica que a dessecação causa irreversíveis danos às membranas das células e à consequente perda da viabilidade (ROBERTS, 1973b).

Observou-se que as sementes de jabuticabeira são moderadamente recalcitrantes (moderada tolerância à dessecação), segundo a classificação de Farrant et al. (1988), e que o grau de umidade letal, que representa o limite a partir do qual todas as sementes perdem a viabilidade (HONG; ELLIS, 1992), foi entre 10 e 13\%. Para o camu-camu (Myrciaria dubia), outra fruteira da família Myrtaceae, nativa da Amazônia, Gentil e Ferreira (2000) observaram que o grau de umidade letal foi em torno de $19 \%$.

Farrant et al. (1988) observaram que as sementes alta e moderadamente recalcitrantes são sensíveis a baixas temperaturas. Isso foi demonstrado no presente trabalho, pois as sementes de jabuticabeira perderam a viabilidade mais rapidamente sob temperaturas mais baixas $\left(12^{\circ} \mathrm{C} \mathrm{e} 6^{\circ} \mathrm{C}\right)$ em comparação à temperatura ambiente (média de $17^{\circ} \mathrm{C}$ ). Porém temperaturas altas também prejudicam a germinação, 
pois Andrade e Martins (2003) observaram que a germinação de sementes de jabuticabeira foi maior quando submetidas a $15^{\circ} \mathrm{C}$ e $20^{\circ} \mathrm{C}$, em comparação a temperaturas acima de $25^{\circ} \mathrm{C}$.

\section{Experimento 2}

Para a emergência das plântulas, houve interação significativa entre os fatores testados (condição de armazenamento x período de armazenamento). Ocorreu redução linear da viabilidade das sementes com o armazenamento. Entretanto, até 35 dias do armazenamento, a emergência foi similar entre as condições de armazenamento (65\%). A partir daí, o tratamento das sementes com tampão fosfato manteve maior viabilidade das sementes, que foi de $41,7 \%$ aos 65 dias de armazenamento, enquanto com água foi de $36,2 \%$, e o pior tratamento foi a seco, no qual as sementes apresentaram emergência de apenas 8,3\% aos 65 dias (Figura 1).

Pelas equações de regressão, pode-se predizer que, se as sementes de jabuticabeira forem embaladas a vácuo com tampão fosfato, há redução de $0,68 \%$ de emergência a cada dia de armazenamento; para o tratamento com água, essa redução é de $0,75 \%$ e, no tratamento a seco, é de $1,3 \%$ a cada dia de armazenamento.

O IVE também foi influenciado significativamente pela interação entre os fatores testados. Houve redução linear do IVE com o passar dos dias de armazenamento, de forma semelhante à emergência, ou seja, a redução do IVE foi menor quando se utilizou o tratamento com tampão fosfato, intermediária com água e maior quando as sementes foram mantidas secas (Figura 2).

A emergência de sementes sem armazenamento (na data de coleta) foi de $92 \pm 1,8 \%$ e o IVE de 1,54 $\pm 0,05$, valores superiores aos encontrados por Danner et al. (2007). O valor de IVE das sementes do segundo experimento foi maior que das sementes utilizadas no primeiro experimento, o que pode ser explicado pelo fator genético, visto que foram coletadas de plantas diferentes, havendo diferença de vigor.

Apenas para a variável percentual de poliembrionia houve falta de homogeneidade da variância, a qual foi obtida após transformação dos dados originais à escala logarítmica. A taxa de poliembrionia das sementes armazenadas foi, em média, de $41,3 \%$ e não foi influenciada significativamente pelas condições e pelo tempo de armazenamento. Isto evidencia que outros fatores influenciam na taxa de poliembrionia, podendo ser o principal a influência genética e as condições ambientais durante a embriogênese somática de sementes na planta-matriz.

Nas sementes poliembriônicas, normalmente, há um embrião zigótico, formado pela fecundação, e um ou mais embriões assexuais, formados por apomixia (embriogênese somática), os quais geram plantas que são clones da planta-mãe. Gurgel e Soubihe Sobrinho (1951) observaram que o número de embriões por semente de jabuticabeira variou de 1,13 a 1,85 nos diversos genótipos avaliados. Esse processo apresenta grande potencial para o melhoramento genético, através da propagação clonal de genótipos superiores usando sementes. Porém, esse potencial ainda é pouco conhecido e explorado (KOLTUNOW; GROSSNIKLAUS, 2003). No caso da jabuticabeira, primeiramente, é necessário desenvolver uma técnica para diferenciar precocemente a planta zigótica daquelas não zigóticas.

A umidade inicial das sementes (sem armazenamento) foi de $46,6 \%$. Quando armazenadas em água, as sementes aumentaram a umidade, em média, para $60,5 \%$ e, em tampão fosfato, para média de $57,3 \%$, até o $65^{\circ}$ dia de armazenamento. O armazenamento das sementes a seco permitiu a manutenção da umidade das sementes, que foi de $46,6 \%$ em média, até os 65 dias de armazenamento.

Assim, observa-se que apenas a modificação da atmosfera, com embalagem a vácuo, permitiu a manutenção da umidade das sementes. Isso porporcionou a manutenção de boa viabilidade (próximo de 65\%) até $\mathrm{o} 35^{\circ}$ dia de armazenamento, como já demonstrado (Figura 1). Entretanto, após esse período, mesmo com a manutenção da umidade das sementes, sua viabilidade foi drasticamente reduzida na embalagem a seco, mas mantida em níveis razoáveis na presença de água e, principalmente, de tampão fosfato. Provavelmente, esses auxiliaram na manutenção da integridade da parede celular e da atividade enzimática, visto que o tampão fosfato é utilizado na determinação de atividade de enzimas, por favorecer a manutenção da integridade de proteínas (NSIMBA-LUBAKI et al., 1983). Valio e Ferreira (1992) também observaram que, após 20 dias de armazenamento a seco em sacos de polietileno, as sementes de jabuticabeira apresentaram baixa germinação (10\%), apesar de conter 50\% de teor de água.

Os resultados apresentados neste trabalho demonstram que, quando for necessário o armazenamento de sementes de jabuticabeira (Plinia cauliflora), esse deve ser feito em embalagem a vácuo seco, até 35 dias, ou com tampão fosfato $\mathrm{pH}$ 7,0, se for por período maior. Esses resultados favorecem a eficiência no intercâmbio de germoplasma de jabuticabeira entre instituições de pesquisa e facilitam o escalonamento de semeadura em viveiros de mudas. 
TABELA 1- Emergência, Índice de velocidade de Emergência (IVE) e poliembrionia de sementes de jabuticabeira (Plinia cauliflora) após cinco dias de armazenamento sob diferentes temperaturas.

\begin{tabular}{cccc}
\hline Temperatura & Emergência (\%) & IVE & Poliembrionia (\%) \\
\hline Ambiente & $83,35 \mathrm{a}$ & $0,51 \mathrm{a}$ & $37,50^{\mathrm{NS}}$ \\
$12^{\circ} \mathrm{C}$ & $41,65 \mathrm{~b}$ & $0,29 \mathrm{~b}$ & 25,00 \\
$6^{\circ} \mathrm{C}$ & $33,33 \mathrm{~b}$ & $0,15 \mathrm{~b}$ & 25,00 \\
\hline $\mathrm{CV}(\%)$ & 34,3 & 1,3 & 112,4 \\
\hline
\end{tabular}

Médias seguidas de letras distintas diferem entre si, pelo teste de $\operatorname{Scott-Knott~}(P \leq 0,05)$. Ns: não significativo pelo teste $\mathrm{F}(P \leq 0,05)$.

TABELA 2 - Teor de água (\%) de sementes de jabuticabeira (Plinia cauliflora) submetidas a diferentes períodos e temperaturas de armazenamento.

\begin{tabular}{cccc}
\hline & \multicolumn{3}{c}{ Temperatura de armazenamento } \\
\cline { 2 - 4 } Período de armazenamento (dias) & Ambiente & $12^{\circ} \mathrm{C}$ & $6{ }^{\circ} \mathrm{C}$ \\
\hline 5 & 19,6 & 16,0 & 13,7 \\
10 & 9,9 & 9,6 & 8,9 \\
20 & 8,1 & 7,6 & 7,0 \\
40 & 6,7 & 6,3 & 5,7 \\
80 & 5,4 & 5,1 & 5,0 \\
\hline
\end{tabular}

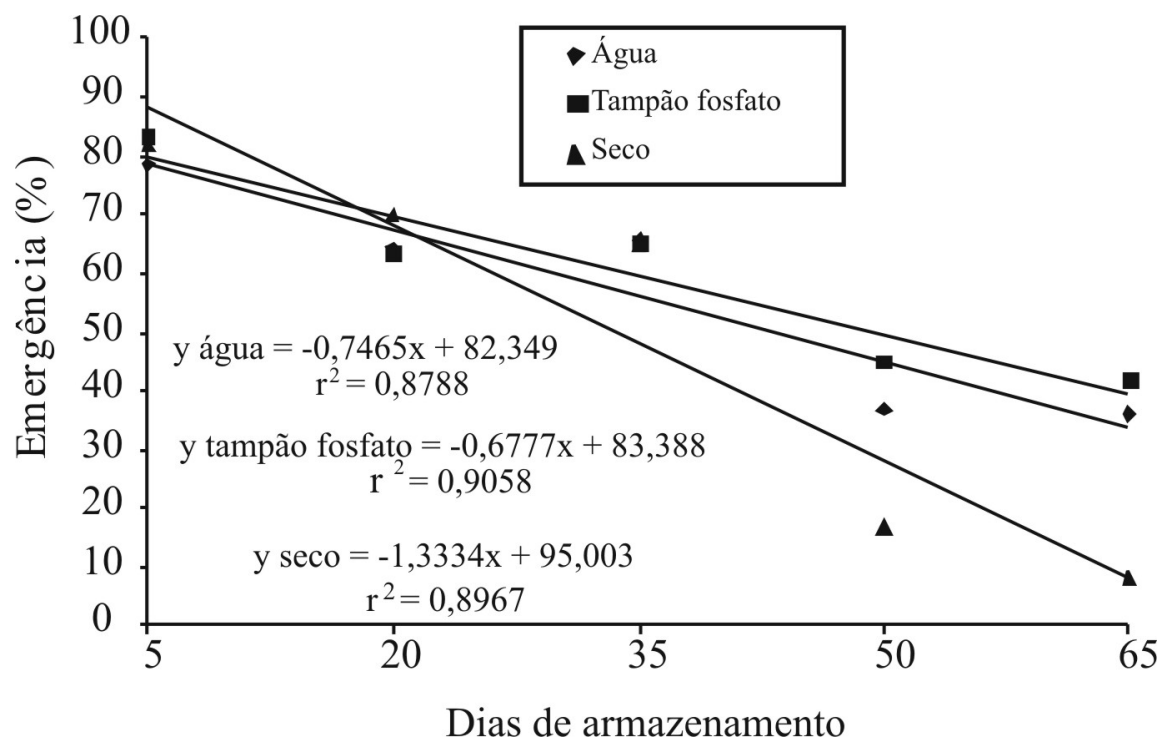

FIGURA 1 - Emergência de plântulas de jabuticabeira (Plinia cauliflora) em função das condições e do período de armazenamento. $\mathrm{CV}(\%)=24,5$. 


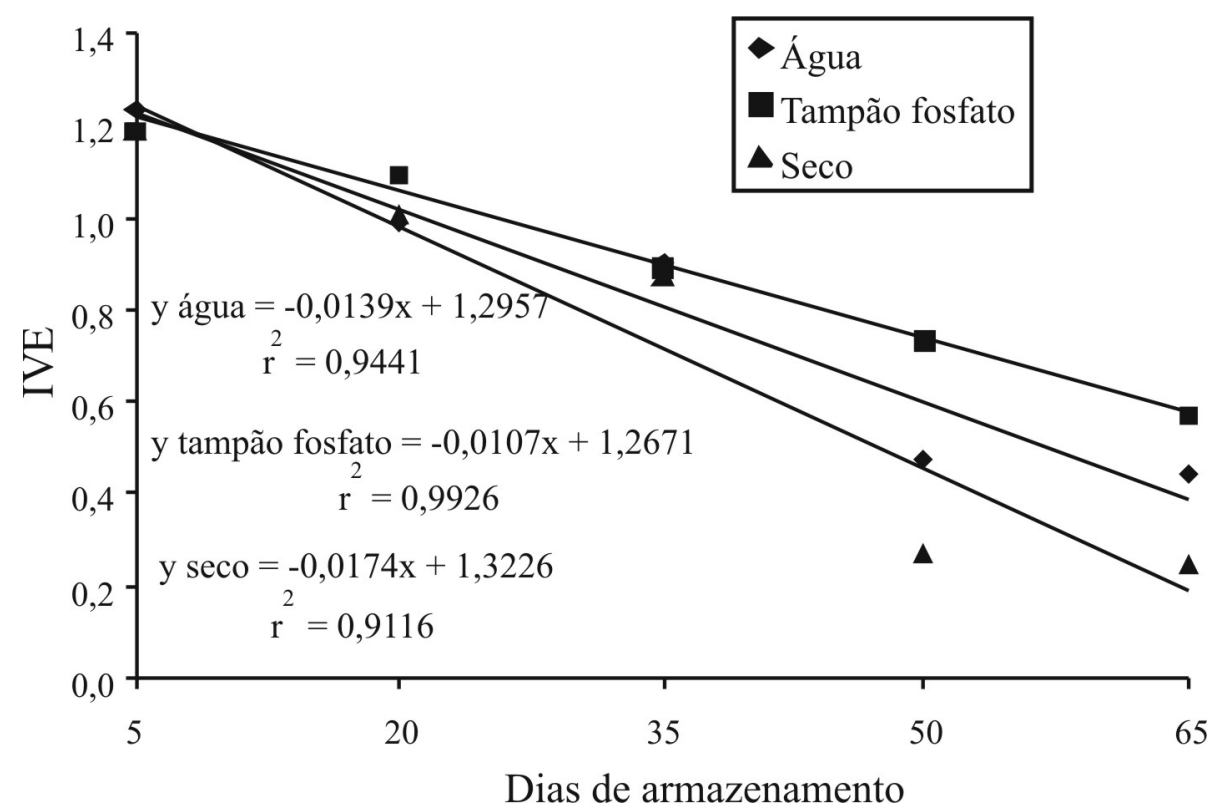

FIGURA 2 - Índice de velocidade de emergência (IVE) de plântulas de jabuticabeira (Plinia cauliflora) em função das condições e do período de armazenamento. $\mathrm{CV}(\%)=32,8$.

\section{CONCLUSÕES}

Nas condições experimentais testadas, conclui-se que:

1-Sob atmosfera normal, as sementes de jabuticabeira conservam-se por apenas cinco dias, mantendo maior viabilidade sob temperatura ambiente.

2-As sementes de jabuticabeira perdem totalmente a viabilidade com teor de umidade próximo a $10 \%$.

3-As sementes de jabuticabeira armazenadas a vácuo com tampão fosfato mantêm razoável viabilidade até 65 dias de armazenamento.

\section{REFERÊNCIAS}

ANDRADE, R.A.; MARTINS, A.B.G. Influence of the temperature in germination of seeds of jabuticaba tree. Revista Brasileira de Fruticultura, Jaboticabal, v.25, n.1, p.197-198, 2003.

CRUZ, C.D. Programa genes: estatística experimental e matrizes. Viçosa: Universidade Federal de Viçosa, 2006. 285p.
DANNER, M.A.; CITADIN, I.; JUNIOR, A.A.F.; ASSMAN, A.P.; MAZARO, S.M.; DONAZZOLO, J.; SASSO, S.A.Z. Enraizamento de jabuticabeira (Plinia trunciflora) por mergulhia aérea. Revista Brasileira de Fruticultura, Jaboticabal, v.28, n.3, p.530-532, 2006.

DANNER, M.A.; CITADIN, I.; JUNIOR, A.A.F.; ASSMAN, A.P.; MAZARO, S.M.; SASSO, S.A.Z. Formação de mudas de jabuticabeira (Plinia cauliflo$r a$ ) em diferentes substratos e tamanhos de recipientes. Revista Brasileira de Fruticultura, Jaboticabal, v.29, n.1, p.179-182, 2007.

DUARTE, O.R.; HUETE, M.; LÜDDERS, S.P. Propagation of jabuticaba (Myrciaria cauliflora (Mart.) Berg.) by terminal leafy cuttings. Acta Horticulturae, Wageningen, n.452, p.123-128, 1997.

FARRANT, J.M.; PAMMENTER, N.W.; BERJAK, P. Recalcitrance: a current assessment. Seed Science \& Technology, Zurich, v.16, n.1, p.155-166, 1988.

GENTIL, D.F.O.; FERREIRA, S.A.N. Tolerância à dessecação e viabilidade de sementes de camu-camu. Revista Brasileira de Fruticultura, Jaboticabal, v.22, n.2, p.264-267, 2000. 
GURGEL, J.T.A.; SOUBIHE SOBRINHO, J. Poliembrionia em mirtáceas frutíferas. Bragantia, Campinas, v.11, n.4-6, p.141-163, 1951.

HONG, T.D.; ELLIS, R.H. Optimum air-dry seed storage environments for arabica coffee. Seed Science \& Technology, Zurich, v.20, n.2, p.547-560, 1992.

KOLTUNOW, A.M.; GROSSNIKLAUS, U. Apomixis: a developmental perspective. Annual Review of Plant Biology, Palo Alto, v.54, p.547-574, 2003.

MAGALHÃES, M.M.; BARROS, R.S.; FINGER, F.L. Changes in non-structural carbohydrates in developing fruit of Myrciaria jaboticaba. Scentia Horticulturae, Amsterdam, v.66, n.1-2, p.17-22, 1996.

MATTOS, J.L.R. Frutíferas nativas do Brasil: jaboticabeiras. Porto Alegre: Nobel, 1983. 92p.

NSIMBA-LUBAKI, M.; PNEUMANS, W.J.; CARLIER, A.R. Isolation and part characterization of a lectin from Euphorbia heterophylla seeds. Biochemistry Journal, Tokyo, v.215, p.141-145, 1983.

ROBERTS, E.H. Predicting the storage life of seeds. Seed Science \& Technology, Zurich, v.1, n.2, p.499-514, 1973a.

ROBERTS, E.H. Loss of viability: ultrastructural and physiological aspects. Seed Science \& Technology, Zurich, v.1, n.2, p.529-545, 1973 b.
SASSO, S.A.Z. Propagação vegetativa de jabuticabeira. 2009. 64 f. Dissertação (Mestrado em Agronomia) - Universidade Tecnológica Federal do Paraná, Pato Branco, 2009.

SASSO, S.A.Z.; CITADIN, I.; DANNER, M.A. Propagação de jabuticabeira por enxertia e alporquia. Revista Brasileira de Fruticultura, Jaboticabal, v.32, n.2, p.571-576, 2010.

SCARPARE FILHO, J.A.; NETO, J.T.; COSTA, J.W.H.; KLUGE, R.A. Efeito do ácido indolbutírico no enraizamento de estacas herbáceas de jabuticabeira Sabará (Myrciaria jabuticaba), em condições de nebulização. Revista Brasileira de Fruticultura, Jaboticabal, v.21, n.2, p.146-149, 1999.

STEEL, R.G.D.; TORRIE, J.H. Principles and procedures of statistics. Nova York: McGraw Hill Book, 1960. 481p.

TEIXEIRA, L.N.; STRINGHETA, P.C.; OLIVEIRA, F.A. Comparação de métodos para quantificação de antocianinas. Ceres, Viçosa, MG, v.55, n.4, p.297304, 2008 .

VALIO, I.F.M.; FERREIRA, Z.L. Germination of seeds of Myrciaria cauliflora (Mart.) Berg. (Myrtaceae). Revista Brasileira de Fisiologia Vegetal, Lavras, v.4, n.2, p.95-98, 1992. 